\title{
A Study on the Validity of the Grammar Fill-in- the-blank Questions of the National English Paper for College Entrance Examination in 2020
}

\author{
Shasha Li \\ School of Foreign Language, China West Normal University, Nanchong, Sichuan, China
}

\begin{abstract}
Grammar fill-in-the-blank is different from previous single-choice questions. It uses text as a carrier to test students' English ability, instead of traditional multiple-choice questions. However, is it better than the single-choice test? Is it effective? Taking the grammar filling-in-the-blank questions of the 2020 National College Entrance Examination Papers 1, 2 and 3 as the research object, starting from the grammar filling-in-the-blank, combined with the students' expected answers, this article conducts an analysis and investigation. The results show that grammar fill-in-the-blank questions are highly effective, which can examine students' grammatical ability. However, some test points are still limited to the level of words or phrases, so the discourse function is not fully utilized. In this regard, the author puts forward specific suggestions for improvement.
\end{abstract}

Key words: National College Entrance Examination English Paper; grammar fill-in-the-blank; content validity

\section{Introduction}

Grammar fill in the blank is to test students' overall discourse ability from the aspect of grammar. This question type is a new type of test exercise. An 200-word article has 10 spaces, some of which have hint words. Students must fill in the blanks with appropriate words based on the context of the article and their vocabulary and grammatical knowledge, such as part-of-speech words, tense verbs, nouns, conjunctions, pronouns, articles, etc. The purpose of filling in the blank exercises is to check the students' grammar knowledge, pragmatic ability and comprehensive language ability. In terms of creativity and innovation in grammar filling in the blanks, on the one hand, it can evaluate students' vocabulary and grammar knowledge based on context. On the other hand, it requires students to output internalized knowledge content instead of multiple-choice exercises. The investigation of English is not just knowledge itself. Therefore, the changes in the content and form of the college entrance examination questions have further promoted the transformation of the knowledge-based teaching. This research analyzes the validity of the grammar filling in the blanks, hoping to make certain suggestions for the improvement of the test questions, and also have inspirations for teaching.

\section{Related Research}

Since the mid-1980s, with the development of CLT, linguists have conducted in-depth research and discussion on language communicative competence. Especially Bachman puts forward a more comprehensive theory of communicative language ability in the 1990s. Communicative language test (CLT) is also called psycho-social linguistic test, in which 
reliability and validity are very important. According to Bachman's point of view, the test method is very important for the research and analysis of the language ability, and it has an essential influence on the reliability of the test score. The test mode includes the following five parts: the test environment, questions, the input received by the examinee, the expected response of the input, and the relationship between the input and the expected response. The theory provides a relatively complete outline for researchers who want to develop communication testing. The purpose of the communicative language proficiency test is to test the candidate's ability.

Testing is an important means of language teaching, and validity is the most important quality indicator in language testing. Therefore, how to deal with the balance of reliability and validity under certain conditions is the primary issue to improve the overall validity of the test. Test validity is a crucial test measurement standard. Specifically, validity refers to whether the test has checked the internal content expected by the test designer, and whether the test result can truly reflect the student's language ability. According to its rich connotation, Hughes (1989) believes that validity can be divided into 3 points: 1) surface validity, which is surface credibility or public acceptance; 2) content validity, which is content validity measurement tools (including materials, topics), and the subject is representative or the content of the selected sample is sufficient; 3) relevance validity. The test of relevance and independence are quite reliable measurement tools. According to its function, validity can be divided into concurrency validity, prediction validity and construct validity.

\section{Research Design}

\subsection{Research questions}

This article aims to explore the following three aspects: (1) Is the grammar fill-in-the-blank question valid for the 2020 college entrance examination English national paper? (2) Are the 3 sets of grammar fill-in-the-blank questions reasonably distributed among test sites? (3) Is the setting factor of the grammar fill-in-the-blank appropriate?

\subsection{Research objects}

This research is based on the text materials of the grammar fill-in-the-blank (an English essay of about 200 words) of the 3 sets of national English test papers for the 2020 College Entrance Examination. Grammar fill-in-the-blank requires students to fill in appropriate words in the blanks of the essay based on the context of the article and their own vocabulary and grammar knowledge.

\subsection{Research tools}

This article adopts the text analysis method to analyze the grammar fill-in questions of the 2020 National College Entrance Examination English from the aspects of genre, text length, legibility, and space setting. It takes into account the General High School English Curriculum Standards and Bachman \& Palmer's test tasks. The theoretical framework is analyzed from the input text and expected answer characteristics. The input text refers to the material of the grammar fillin-the-blank question, and the expected response refers to the feedback of the students on the test content. Li Xiaoju believes that the level and focus of test questions will also affect the validity of language tests. The level of the test is positively correlated with the subject's language ability. At the same time, the level of the test is also related to the importance of the focus of the test. The focus of the test is generally divided into grammar and meaning. Based on the testing framework of Bachman \& Palmer and combined with Li Xiaoju's analysis theory, this paper analyzes the validity of the grammar fill-in section of the 2020 National College Entrance Examination Paper.

\section{Results and Discussion}

\subsection{Analysis of discourse input features}

This research conducts a discourse analysis of the grammar fill-in-the-blank questions of the three English test papers of the College Entrance Examination in 2020, including genre, subject matter, article length and space. 
Table 1. Features of text input

\begin{tabular}{|c|c|c|c|}
\hline & National Volume 1 & National Volume 2 & National Volume 3 \\
\hline Genre & Explanatory text & Explanatory text & Narrative text \\
\hline Subject & Social Science & Social Humanities & Character Experience \\
\hline Article length & 189 & 193 & 214 \\
\hline Maximum distance & 36 & 43 & 44 \\
\hline Minimum distance & 5 & 5 & 18.3 \\
\hline Average distance & 15.5 & 16 & 4 \\
\hline
\end{tabular}

(1) Genre

Article genre refers to the style of the article. From the analysis results of Table 1, it can be seen that the 2020 College Entrance Exam English National Volume 1 and National Volume 2 Grammar Fill-in are explanatory texts, and the National Volume 3 Grammar Fill-in Blanks is a narrative, none of the three sets of test questions involve argumentative essays and practical essays. This is because the purpose of the fill-in exercise is to check the students' vocabulary and vocabulary grammar knowledge, pragmatic ability and comprehensive language ability. The text should not be too difficult. Narrative essays and explanatory essays are the most common text genres in students' daily practice, and their level of difficulty is within the range of students' abilities. Therefore, using this type of text to examine students' language ability meets the requirements of the course standard.

\section{(2) Subject}

From the analysis results in Table 1, it can be seen that the topics of grammar filling in 3 sets of test questions in the 2020 College Entrance Examination English National Paper involve social science, social humanities, and character experience. Among them, National Volume 1 is an explanatory essay. Keeping abreast of current events, it talked about Chinese launch of Chang'e-4 to explore the moon. It is not only a test of students' ability to use English, but also a test of students' knowledge. The National Volume 2 is an explanatory essay that introduced the meaning of decorating Chinese New Year with some plants, fruit and flowers, which can guide students to establish a correct ideology. The National Volume 3 is a fable, which aimed to tell us that there are many things to learn from nature, and the most important thing is humility. The charm of man and nature makes the artist's experience meaningful. The article showed students the beauty between man and nature. The 3 sets of grammar fill-in-the-blank questions in the 2020 College Entrance Examination English National Test Paper are closely related to students' daily life and convey positive thematic meanings to students.

\section{(3) Article length}

This study counts the number of words in the grammatical blanks in 3 sets of test questions. From the analysis results in Table 1, it can be seen that the number of grammatical blanks in the three sets of test questions is about 200. Among them, the longest National Volume 3 has 214 words, and the shortest National Volume 1 has 189 words, with a difference of 25 words, and the text length is relatively stable.

(4) Set space distance

In English test, the space of the blanks of grammar and the difficulty level of the test are related to each other. Heaton believes that both too short and too long of a spatial distance will result in poor test validity, and the fluctuation range of 510 words is reasonable. It can be seen from Table 1 that the maximum spacing of the three sets of test questions is between 35-45 words, and the minimum spacing is controlled within a reasonable range. However, the average spacing of the three sets of grammar fill-in-the-blank questions all exceeded 15 words, and the National Volume 3 even reached 18 words. The average spacing fluctuated greatly. 
4.2 Analysis of expected response characteristics

Content distribution of test sites: The grammar fill-in-the-blank are divided into two types: with word prompts and without word prompts. Among them, prompt words are mainly based on content words, and unprompted words are mostly based on fixed phrase collocations or the logical meaning of the article.

Table 2. Content distribution of test sites

\begin{tabular}{|c|c|}
\hline Article & $\begin{array}{l}\text { the+ singular countable noun/plural noun/uncountable (the table specifically refers to } \\
\text { "this/these") (Volume } 1 \mathrm{~T} 70 \text { ) }\end{array}$ \\
\hline Preposition & Custom collocation usage (Volume I T67, Volume 2 T70) \\
\hline Conjunction & $\begin{array}{l}\text { (1) Leading words of attributive clauses (Volume } 1 \text { T63, Volume } 2 \text { T61) } \\
\text { (2) Guiding words of adverbial clauses (Volume T 65, Volume } 2 \text { T65) }\end{array}$ \\
\hline Verb & $\begin{array}{l}\text { (1) Predicate verbs (tenses and voices, subject-predicate agreement, modal verbs, subjunctive } \\
\text { mood, Divine sentence) (Volume } 1 \text { T61, 67, 68, Volume } 2 \text { T62, Volume } 3 \text { T63, 66) } \\
\text { (2) Non-predicate verbs (infinitives, participles, gerunds) (Volume } 1 \text { T66, Volume } 2 \text { T63, 65, } \\
68 \text {, Volume } 3 \text { T67,69) } \\
\text { (3) Part of speech conversion (conversion into nouns, adjectives) (Volume } 2 \text { T61) }\end{array}$ \\
\hline Noun & Part-of-speech conversion (conversion to adjectives) (Volume 2 T69) \\
\hline Adjective/adverb & $\begin{array}{l}\text { (1) Correct use of adjectives and adverbs (adjectives become adverbs) (Volume } 1 \text { T62, Volume } \\
\qquad 2 \text { T66, Volume } 2 \mathrm{~T} 68 \text { ) } \\
\text { (2) The comparative level of adjectives/adverbs (Volume } 2 \mathrm{~T} 62 \text { ) } \\
\text { (3) Part of speech conversion (conversion into nouns) (Volume 1 T64, Volume } 2 \text { T64) }\end{array}$ \\
\hline Pronoun & The usage of adjective possessive pronouns and nominal possessive pronouns (Volume 1 T70) \\
\hline
\end{tabular}

According to the test site distribution table, it can be seen that the high-frequency test sites mainly focus on articles, prepositions, conjunctions, nouns, verbs, and adjectives, and the focus of each test site is different:

(1) The frequent test sites for pure blank questions are articles, prepositions and conjunctions. Articles mainly examine the usage and basic usage of articles in fixed collocations. Prepositions mainly examine the basic usage of prepositions and habitual collocation usage. Conjunctions mainly examine the introductory words of attributive clauses and adverbial clauses. The guiding words and coordinating conjunctions of nominal clauses are not examined.

(2) The high-frequency test sites with prompt words are verbs, adjectives and nouns. Verbs mainly examine the tense and voice of verbs, non-predicate verbs and part-of-speech conversion Adjectives mainly examine the correct use of adjectives and adverbs and compare levels. Nouns mainly examine part of speech conversion, singular and plural are not examined.

In short, the 2020 National Volume 1 grammar fill-in-the-blank questions are somewhat difficult. First of all, the text is a science and technology text with complex sentence structure and difficult to understand. Secondly, there are a few more difficult questions. Especially for question 65, "more so than the familiar near side", if the examinee is not interested in science, it is difficult to find ideas for solving the problem and easy to make mistakes. There is also question 63 , "Because the moors body blocks direct radio communication with a probe, China first had to put a satellite in orbit above the moon in a spot where it could send signals to the spacecraft and to ear". This sentence structure is complicated, which is difficult to understand, so it is impossible to judge whether it is an attributive clause. On the whole, it is not easy to get a 
high score for the 2020 National Volume 1 Grammar Fill-in Questions. But it is not difficult to fill in the grammar questions in the National Volume 2 and 3 of the 2020 College Entrance Examination. Because the content of the text is close to life and the article is not difficult to understand, the test sites conforms to the syllabus, and mainly focuses on the title, introduction, connection, and movement covered by the syllabus.

Grammar fill in the blank is to put grammatical points in the text and test the students' comprehensive language ability. Therefore, examining students' language ability in discourse requires students to combine context and language knowledge, and use learning strategies and language skills to complete tasks. The 2020 College Entrance Examination English National Paper grammar fill-in-the-blank mainly focus on the examination of grammar knowledge, ignoring the examination of meaning.

\section{Conclusions and Recommendations}

\subsection{Research conclusions}

The 3 sets of grammar fill-in-the-blank basically meet the requirements of testing language ability in the text, and they have high content validity. The grammar fill-in-the-blank questions of the 3 sets of test questions are of moderate difficulty and are all within the scope of students' abilities. The 3 sets of test questions include fill-in-the-blanks with prompt words and fill-in-the-blanks with no prompt words, and the distribution distance of test sites is balanced overall. At the same time, the topic selection is also relatively diverse, the topic selection is suitable for the actual situation of the examinee, and has a certain communicative and enlightening nature. In addition, the test questions also need to be improved. For example, the type of style only involves explanatory text and narrative, ignoring other styles. The distance between individual items fluctuates greatly, which leads to the low effect of the examination to a certain extent.

\subsection{Suggestions}

Under the influence of grammar filling in the blanks, teachers should integrate the teaching ideas of grammar filling in the blanks into teaching practice, and use the teaching ideas of grammar filling in the blanks to guide them in teaching practice instead of using vocabulary and grammar practice. At the same time, I suggest that the genre of grammar filling in the blanks can be more diversified, which will also help teachers pay attention to the wide range of students' reading in teaching, rather than blindly mechanical training. At the same time, attention should be paid to the reasonable distribution of space distance. Even distribution does not mean reasonable, it is also necessary to consider different styles to set the corresponding space distance.

In addition, the test sites focuses heavily on grammatical and collocation factors, which violates the original purpose of the test questions and is just a textbook-style test. Therefore, due consideration should be given to the examination of meaning factors, so that the students' language ability can be examined in all aspects. For high school English teaching, teachers should strengthen the training of students' basic language knowledge. In addition to consolidating language knowledge and language skills, cultural knowledge and learning strategies should also be cultivated accordingly. In ordinary teaching, we pay attention to the input of diverse language texts for students. At the same time, teachers should encourage students to expand learning resources, provide students with more channels to learn languages and more opportunities to use English language.

\section{Conflicts of Interest}

The author declares no conflicts of interest regarding the publication of this paper.

\section{References}

[1] Alderson J. C., Clapham C. and Wall D. (2000). Language Testing Construction and Evaluation. Foreign Language Teaching and Research Press, Beijing. 
[2] Bachman L.F. (1990). Fundamental Considerations in Language Testing. Oxford University Press, Oxford.

[3] Heaton J..B., Harmer J. and Kingsbury R. (2000). Writing English Language Test. Foreign Language Teaching and Research Press, Beijing.

[4] Hughes A. (1989). Testing for Language Teachers. Cambridge University Press.

[5] Gu X.D. and Wang Q.Y. (2008). An Analysis of the Content Validity of the Reading Comprehension Test Questions of the National English Paper for College Entrance Examination and the Autonomous Test Papers of Provinces and Cities. Examinations Research, (3):102-114.

[6] Han B.C. (2000). Statistical Methods in Foreign Language Teaching and Research. Foreign Language Teaching and Research Press, Beijing.

[7] Li X.J. (1997). The Science and Art of Language Testing. Hunan Education Publishing House, Hunan.

[8] Liu R.Q. and Han B.C. (1991). Language Testing and Its Methods. Foreign Language Teaching and Research Press, Beijing.

[9] Ministry of Education. (2018). General High School English Curriculum Standards (2017 edition). People's Education Press, Beijing.

[10] Ministry of Education. (2018). 2019 General College Admissions National Examination Syllabus (English). Higher Education Press, Beijing.

[11] Zhang C.Q. (2015). The Rasch Model Analysis of the Constructive Validity of the English Grammar Fill-in-theblank Questions in the College Entrance Examination. Modern Foreign Languages, (02):258-268+293. 